\title{
Gene microarray analysis of expression profiles in liver ischemia and reperfusion
}

\author{
XIAOYANG ZHENG ${ }^{1 *}$, HUAQIANG ZHOU ${ }^{2 *}$, ZETING QIU $^{1}$, \\ SHAOWEI GAO ${ }^{1}$, ZHONGXING WANG $^{1}$ and LIANGCAN XIAO ${ }^{1}$ \\ ${ }^{1}$ Department of Anesthesiology, The First Affiliated Hospital, Sun Yat-sen University, Guangzhou, Guangdong 510058; \\ ${ }^{2}$ Zhongshan School of Medicine, Sun Yat-sen University, Guangzhou, Guangdong 510080, P.R. China
}

Received October 24, 2016; Accepted May 26, 2017

DOI: $10.3892 / \mathrm{mmr} .2017 .6966$

\begin{abstract}
Liver ischemia and reperfusion (I/R) injury is of primary concern in cases of liver disease worldwide and is associated with hemorrhagic shock, resection and transplantation. Numerous studies have previously been conducted to investigate the underlying mechanisms of liver I/R injury, however these have not yet been fully elucidated. To determine the difference between ischemia and reperfusion in signaling pathways and the relative pathological mechanisms, the present study downloaded microarray data GSE10657 from the Gene Expression Omnibus database. A total of two data groups from 1-year-old mice were selected for further analysis: i) A total of $90 \mathrm{~min}$ ischemia; ii) $90 \mathrm{~min}$ ischemia followed by $1 \mathrm{~h}$ of reperfusion, $\mathrm{n}=3$ for each group. The Limma package was first used to identify the differentially expressed genes (DEGs). DEGs were subsequently uploaded to the Database for Annotation Visualization and Integrated Discovery online tool for Functional enrichment analysis. A protein-protein interaction (PPI) network was then constructed via STRING version 10.0 and analyzed using Cytoscape software. A total of 114 DEGs were identified,
\end{abstract}

Correspondence to: Dr Zhongxing Wang or Dr Liangcan Xiao, Department of Anesthesiology, The First Affiliated Hospital, Sun Yat-sen University, 58 Zhongshan 2nd Road, Guangzhou, Guangdong 510058, P.R. China

E-mail: doctorwzx@126.com

E-mail: xiaolc@21cn.com

${ }^{*}$ Contributed equally

Abbreviations: I/R, ischemia and reperfusion; DEGs, differentially expressed genes; DAVID, Database for Annotation Visualization and Integrated Discovery; PPI, Protein-protein interaction network; GEO, network Gene Expression Omnibus database; GO, Gene Ontology; BP, biological process; KEGG, Kyoto Encyclopedia of Genes and Genomes

Key words: gene microarray, liver, ischemia, reperfusion, C-X-C motif chemokine ligand $1, \mathrm{C}-\mathrm{C}$ motif chemokine ligand 2 including 21 down and 93 upregulated genes. These DEGs were primarily enriched in malaria and influenza $\mathrm{A}$, in addition to the tumor necrosis factor and mitogen activated protein kinase signaling pathways. Hub genes identified in the PPI network were $\mathrm{C}-\mathrm{X}-\mathrm{C}$ motif chemokine ligand (CXCL) 1, C-C motif chemokine ligand (CCL) 2, interleukin 6, Jun proto-oncogene, activator protein (AP)-1 transcription factor subunit, FOS proto-oncogene, AP-1 transcription factor subunit and dual specificity phosphatase 1. CXCL1 and CCL2 may exhibit important roles in liver I/R injury, with involvement in the immune and inflammatory responses and the chemokine-mediated signaling pathway, particularly at the reperfusion stage. However, further experiments to elucidate the specific roles of these mediators are required in the future.

\section{Introduction}

Liver ischemia/reperfusion (I/R) injury is caused by blood deprivation and subsequent reperfusion. It caused the release of biological mediators contributing to liver dysfunction eventually (1). Although Liver IR injury is a main complication of hemorrhagic shock, resection and transplantation, its mechanisms haven't been described adequately (2). The pathophysiology of liver I/R injury may include ATP depletion, caused by decrease in oxidative phosphorylation, ROS (reactive oxygen species) creation, cytokines and chemokines production by kupffer cells, neutrophil accumulation, nitric oxide, apoptosis and necrosis (3). For example, liver I/R can induce Kupffer cell activation releasing TNF $\alpha$. The increasing serum TNF $\alpha$ levels resulted in not only liver injury but also remote organ insult (4). Effects on hepatic secretory function and microsomal drug metabolizing systems varied in duration of ischemia or reperfusion. These may be related to lipid peroxidation rise (5). A lot of research suggested that liver I/R injury was age-dependent, which may be associated with neutrophil recruitment and function or NF-kB activation $(6,7)$. The age-related mechanism of $\mathrm{NF}-\kappa \mathrm{B}$ activation in liver I/R injury could be related to recruitment of phosphorylated and ubiquitinylated $\mathrm{NF}-\kappa \mathrm{B}$-inhibitoryprotein, I $\kappa \mathrm{B} \alpha$, to the proteasome. This biological process can be stopped by expression decline of proteasome subunit, non-ATPase 4 (PSMD4) (8). Many methods and drugs had been applied to ameliorate liver I/R 
injury (9-11). Blood supply restoration was a primary step to treat ischemia damage in clinical work. But reperfusion itself may exacerbate organ injury induced by ischemia alone. Many therapeutic strategies should be considered when applied to reduce tissue injury (12). Nowadays, pathways, pivotal genes or cellular functions about liver ischemia and reperfusion, have not been demonstrated clearly. In order to explore more theoretical information about I/R injury precaution and treatment, we tried to compare different molecular mechanisms between liver ischemia followed by reperfusion and ischemia alone.

\section{Materials and methods}

Microarray data. Gene expression profile dataset GSE10657 was obtained from the Gene Expression Omnibus database (GEO, https://www.ncbi.nlm.nih.gov/geo/), including 30 liver tissue samples (8). The annotation platform was GPL1261 [Mouse430_2] Affymetrix Mouse Genome 4302.0 Array. A total of 30 liver tissue samples were collected for analysis of whole mouse genome microarrays. We selected the data of two groups (ischemia of $90 \mathrm{~min}$ and $90 \mathrm{~min}$ of ischemia followed by $1 \mathrm{~h}$ of reperfusion) from 1-year-old mice. Each group included 3 mice.

Data processing. The expression data were processed using the $\mathrm{R}$ package limma in Bioconductor (http://www.bioconductor .org/), including background correction, quantile normalization, $\log 2$ transformed and final probe summarization $(13,14)$. We compared the gene expression of two groups of one-year old mice (ischemia of $90 \mathrm{~min}$ and $90 \mathrm{~min}$ of ischemia followed by $1 \mathrm{~h}$ of reperfusion). The criterion for differentially expressed genes (DEGs) are adjusted P-value $<0.05$ and log2fold-change (FC) $\mid \geq 1$.

Function annotation and KEGG pathway analysis. To explore the biological function of DEGs, we uploaded the target genes to the Database for Annotation, Visualization and Integrated Discovery (DAVID) (https://david-d.ncifcrf. gov/). Gene Ontology (GO) annotation (15) associated with biological process (BP) and Kyoto Encyclopedia of Genes and Genomes (KEGG) (16) pathway enrichment analysis were utilized to analyze the function and potential pathways of these DEGs. The P-value $<0.05$ and gene counts $>2$ were criteria of the both.

PPI network construction. We aimed to identify the possible interaction networks of DEGs by using STRING version 10.0, which covers over 2,000 organisms and provides direct (physical) and indirect (functional) associations (17). DEGs were put in STRING database to construct a PPI network. The confidence score for selection was $\geq 0.4$. Cytoscape (http://www.cytoscape.org/) software was used to dispose the PPI network for visualization.

\section{Results}

Gene expression analysis. After comparing sample records from 1-year-old mice subjected to different conditions (90 min of ischemia followed by $1 \mathrm{~h}$ of reperfusion
Table I. Differentially expressed genes.

\begin{tabular}{|c|c|c|}
\hline Gene & $\log \mathrm{FC}$ & P-value \\
\hline \multicolumn{3}{|l|}{ Upregulated genes } \\
\hline Hspa1a & 4.189803495 & 4.40E-06 \\
\hline Il6 & 3.414377201 & 0.007214798 \\
\hline Hspa1b & 2.835249411 & 0.002570444 \\
\hline Moxd1 & 2.792333639 & 0.005880914 \\
\hline Fos & 2.635607507 & 0.008852822 \\
\hline S100a8 & 2.470587997 & 0.001612021 \\
\hline Atf3 & 2.429293274 & 0.048994575 \\
\hline S100a9 & 2.382088918 & 0.00198724 \\
\hline Thbs 1 & 2.366926809 & 0.002259069 \\
\hline Btg2 & 2.024032519 & 0.036787526 \\
\hline Ctla2a & 1.987516668 & $6.94 \mathrm{E}-07$ \\
\hline Gem & 1.957385710 & $3.11 \mathrm{E}-05$ \\
\hline Egr2 & 1.945932505 & 0.004711597 \\
\hline Ch25h & 1.945386244 & 0.00116547 \\
\hline Cyr61 & 1.884283907 & 0.00418327 \\
\hline Jun & 1.834974240 & 0.02738022 \\
\hline Dnajb1 & 1.834159651 & 0.017880087 \\
\hline Tnfaip6 & 1.783788316 & 0.000235748 \\
\hline $\mathrm{Fgl} 2$ & 1.713266954 & $1.40 \mathrm{E}-05$ \\
\hline Rhob & 1.649879783 & 0.01784261 \\
\hline Junb & 1.559927741 & 0.048521262 \\
\hline Nfkbiz & 1.502336562 & 0.02315746 \\
\hline Apol11b & 1.465232692 & $3.76 \mathrm{E}-05$ \\
\hline Pmaip1 & 1.457536521 & $1.95 \mathrm{E}-06$ \\
\hline Snca & 1.446393501 & 0.002008527 \\
\hline G530011O06Rik & 1.443344075 & 0.000226511 \\
\hline Plscr1 & 1.441607653 & 0.003825377 \\
\hline Dusp1 & 1.421057162 & 0.018558258 \\
\hline Hspb1 & 1.415609621 & 0.012319322 \\
\hline Gm7173 & 1.414339093 & $1.21 \mathrm{E}-07$ \\
\hline Cxcl1 & 1.410753622 & 0.044905834 \\
\hline Hbb-b2 & 1.351033985 & 0.000672398 \\
\hline Adamts1 & 1.329196641 & 0.003830208 \\
\hline Icam1 & 1.290995380 & 0.004126491 \\
\hline 5730412P04Rik & 1.283988337 & $9.54 \mathrm{E}-05$ \\
\hline Rasl11a & 1.282142362 & $6.19 \mathrm{E}-07$ \\
\hline Maff & 1.272068458 & 0.037153789 \\
\hline 2010002N04Rik & 1.271499304 & $1.21 \mathrm{E}-07$ \\
\hline $\operatorname{Rgs} 1$ & 1.251181552 & 0.003312274 \\
\hline 4833405L11Rik & 1.247575574 & $4.51 \mathrm{E}-05$ \\
\hline Zfp36 & 1.234524892 & 0.011557402 \\
\hline $\operatorname{Lcn} 2$ & 1.231778515 & 0.001751743 \\
\hline Klf6 & 1.218441804 & 0.012152268 \\
\hline Chka & 1.213280213 & 0.002802906 \\
\hline Olfr1507 & 1.211292555 & 0.000350502 \\
\hline D530037H12Rik & 1.197701336 & 6.69E-06 \\
\hline $\mathrm{H} 2-\mathrm{gs} 10$ & 1.196542823 & 0.00144295 \\
\hline Fst & 1.193249187 & 0.000621087 \\
\hline Ell3 & 1.182028693 & $3.54 \mathrm{E}-05$ \\
\hline P2ry10 & 1.171525584 & 0.017352901 \\
\hline 2810404M03Rik & 1.167787654 & $5.67 \mathrm{E}-05$ \\
\hline
\end{tabular}


Table I. Continued.

\begin{tabular}{|c|c|c|}
\hline Gene & $\log \mathrm{FC}$ & P-value \\
\hline $\mathrm{Ccl} 2$ & 1.163350947 & 0.002313274 \\
\hline Hsd17b1 & 1.158145456 & 0.000301852 \\
\hline $\mathrm{I} 133$ & 1.142985472 & 0.000393507 \\
\hline C76533 & 1.142247522 & 4.89E-05 \\
\hline Ppbp & 1.137612231 & 0.011227964 \\
\hline $\mathrm{Id} 3$ & 1.132539137 & 0.03950213 \\
\hline Ier3 & 1.130341285 & 0.014790191 \\
\hline 1700016K19Rik & 1.128388132 & 0.000105373 \\
\hline D9Ertd596e & 1.117817849 & $1.34 \mathrm{E}-05$ \\
\hline 1200016E24Rik & 1.106239555 & 0.040908811 \\
\hline Sele & 1.106222576 & 0.002874116 \\
\hline Fam19a1 & 1.097266221 & 4.82E-06 \\
\hline Slfn4 & 1.091663043 & $2.98 \mathrm{E}-05$ \\
\hline Snhg3 & 1.090971444 & 0.002765684 \\
\hline 4833419O12Rik & 1.087463982 & $1.21 \mathrm{E}-07$ \\
\hline Defa21 & 1.081747821 & 0.000252684 \\
\hline Gm10309 & 1.081623512 & $3.19 \mathrm{E}-05$ \\
\hline Spin2 & 1.081365088 & 6.39E-07 \\
\hline 3300002A11Rik & 1.078493847 & 8.17E-06 \\
\hline Pf4 & 1.078344289 & $1.21 \mathrm{E}-07$ \\
\hline 4930469G21Rik & 1.074420496 & 0.000104134 \\
\hline 9530006C21Rik & 1.067140075 & 0.003784627 \\
\hline Procr & 1.060112014 & $3.41 \mathrm{E}-05$ \\
\hline Cebpd & 1.056892489 & 0.009736321 \\
\hline Olfr315 & 1.054905005 & $1.28 \mathrm{E}-06$ \\
\hline Vpreb1 & 1.049741265 & $6.09 \mathrm{E}-07$ \\
\hline Fabp5 & 1.043946536 & 0.046394908 \\
\hline Hbegf & 1.041917009 & 0.002254356 \\
\hline Akr1b7 & 1.038117758 & 0.029888552 \\
\hline 1700010N08Rik & 1.032603816 & $4.55 \mathrm{E}-05$ \\
\hline D9Wsu90e & 1.031933317 & 0.013273235 \\
\hline S100a6 & 1.025678192 & $1.46 \mathrm{E}-05$ \\
\hline Arid5a & 1.023214775 & $5.14 \mathrm{E}-05$ \\
\hline Srgap1 & 1.020638687 & $1.71 \mathrm{E}-07$ \\
\hline Dusp5 & 1.020438070 & $1.17 \mathrm{E}-05$ \\
\hline Gm14085 & 1.018206352 & 0.000563399 \\
\hline $\mathrm{H} 3 \mathrm{f} 3 \mathrm{~b}$ & 1.010059710 & 0.003098606 \\
\hline Cytip & 1.004873236 & 0.025437274 \\
\hline B830004H01Rik & 1.004683417 & 0.000757856 \\
\hline Glipr1 & 1.003361817 & 0.010390201 \\
\hline Apol7b & 1.002402297 & $9.71 \mathrm{E}-05$ \\
\hline Cpne9 & 1.000076745 & $1.21 \mathrm{E}-07$ \\
\hline \multicolumn{3}{|c|}{ Downregulated genes } \\
\hline Cyp4a14 & -1.491686323 & 0.046208079 \\
\hline Igsf6 & -1.357451711 & $1.21 \mathrm{E}-07$ \\
\hline Cacnals & -1.339250877 & 0.000204248 \\
\hline Gucy2c & -1.310550662 & $1.88 \mathrm{E}-07$ \\
\hline Emr4 & -1.269668108 & 0.000244481 \\
\hline C030010L15Rik & -1.235720965 & $3.00 \mathrm{E}-05$ \\
\hline 1500015A07Rik & -1.137485728 & $2.58 \mathrm{E}-05$ \\
\hline AW125324 & -1.097415017 & 7.03E-05 \\
\hline ВC023202 & -1.096162784 & $1.21 \mathrm{E}-07$ \\
\hline
\end{tabular}

Table I. Continued.

\begin{tabular}{lcl}
\hline Gene & $\operatorname{logFC}$ & \multicolumn{1}{c}{ P-value } \\
\hline Gm11818 & -1.083128913 & $1.21 \mathrm{E}-07$ \\
2810404F17Rik & -1.081564746 & $1.21 \mathrm{E}-07$ \\
BC151093 & -1.076581311 & 0.005019689 \\
1700011B04Rik & -1.044376574 & 0.000123774 \\
Otx2os1 & -1.042838602 & 0.001185282 \\
Ttc26 & -1.039636118 & $8.52 \mathrm{E}-07$ \\
4933437I04Rik & -1.036693263 & $1.21 \mathrm{E}-07$ \\
4921513H07Rik & -1.032871132 & $3.95 \mathrm{E}-06$ \\
2010003K10Rik & -1.031683970 & $1.21 \mathrm{E}-07$ \\
Gm9748 & -1.026995861 & $1.92 \mathrm{E}-06$ \\
Adam18 & -1.024258697 & $1.21 \mathrm{E}-07$ \\
9430082L08Rik & -1.006312751 & $1.21 \mathrm{E}-07$ \\
\hline
\end{tabular}

FC, fold-change.

or ischemia of $90 \mathrm{~min}$ ) ( $\mathrm{n}=3$ each group), 114 DEGs were selected to further analysis with the standard ofllog2fold change $(F C) \mid \geq 1$ and adjusted P-values $<0.05$. (Table I and Fig. 1) Among the DEGs, 21 genes were downregulated, while another 93 were upregulated. Cyp4a14, Igsf6 and Cacna1 s were most notably changed of the 21 downregulated genes. Hspa1a, I16, Hspa1b, Moxd1, Fos, S100a8, Atf3, S100a9, Thbs1 and Btg2 were the top ten increased of the 93 DEGs.

GO analysis and KEGG pathway. According to function annotation, the most significant biological processes included immune response (GO:0006955, $\mathrm{P}=1.37 \mathrm{E}-05)$, leukocyte migration involved in inflammatory response (GO:0002523, $\mathrm{P}=1.48 \mathrm{E}-05$ ), inflammatory response (GO:0006954, $\mathrm{P}=5.96 \mathrm{E}-05)$, skeletal muscle cell differentiation (GO:0035914, $\mathrm{P}=1.08 \mathrm{E}-04)$, chemotax is (GO:0006935, $\mathrm{P}=1.82 \mathrm{E}-04$ ), response to lipopolysaccharide (GO:0032496, $\mathrm{P}=3.58 \mathrm{E}-04)$, positive regulation of transcription from RNA polymerase II promoter (GO:0045944, $\mathrm{P}=4.11 \mathrm{E}-04)$, and positive regulation of apoptotic process $(\mathrm{GO}: 0043065, \mathrm{P}=4.96 \mathrm{E}-04)$ (Table II and Fig. 2).

As for highly enriched pathways, TNF signaling pathway $(\mathrm{P}=1.57 \mathrm{E}-06)$, Malaria $(\mathrm{P}=5.41 \mathrm{E}-06)$, Influenza $\mathrm{A}$ $(\mathrm{P}=3.28 \mathrm{E}-05)$, and MAPK signaling pathway $(\mathrm{P}=3.72 \mathrm{E}-04)$ were detected (Table III).

Interaction network construction. All 114 DEGs were put in the String database. A PPI network included 94 nodes and 145 edges was constructed. We analyzed the network by Cytoscape. (Fig. 3) To get more useful information, PPI sub-networks were generated. Nodes with edges more than 6 were CCL2, JUN, CYR61, DUSP1, KLF6, BTG2, ZFP36, IL6, CXCL1, JUNB, NFKBIZ, MAFF, FOS, EGR2 and ATF3 (Fig. 4). Genes with interaction combined-score $\geq 0.9$ were selected to form a PPI sub-network (Fig. 5). Hub proteins were FOS, CCL2, CXCL1, JUN, IL6 and DUSP1, all of which were upregulated. 


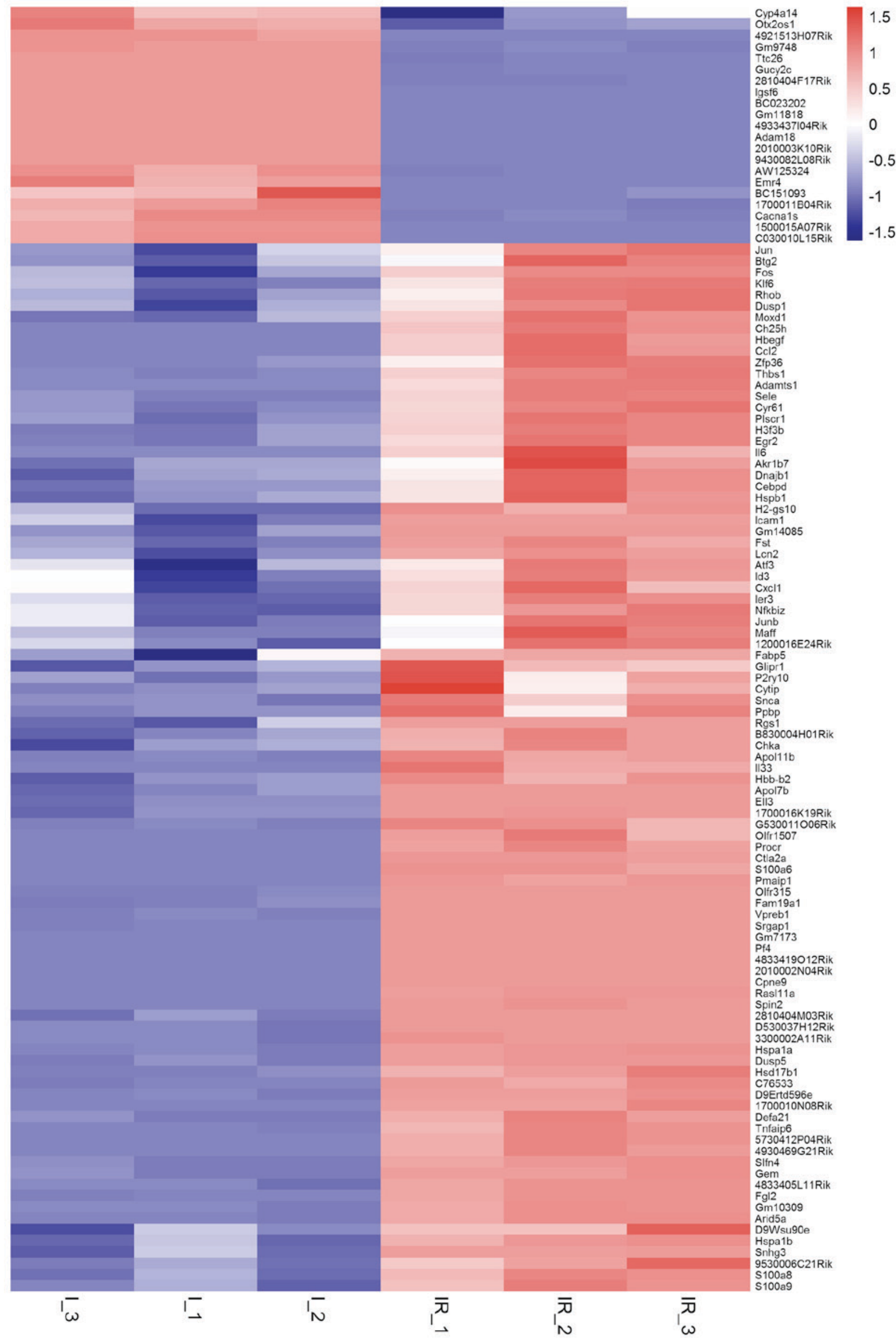

Figure 1. Heat map of DEGs. I_(1-3): 90 min of Ischemia; IR_(1-3): $90 \mathrm{~min}$ of ischemia followed by $1 \mathrm{~h}$ of reperfusion. Colors from blue to red mean increasing expression of DEGs between two groups. DEGs, differentially expressed genes. 
Table II. GO biological process for DEGs (top 10).

\begin{tabular}{llrl}
\hline GO ID & & \multicolumn{1}{c}{ GO Term } & Count \\
\hline GO:0006955 & Immune response & 9 & $1.37 \mathrm{E}-05$ \\
GO:0002523 & Leukocyte migration involved in inflammatory response & 4 & $1.48 \mathrm{E}-05$ \\
GO:0006954 & Inflammatory response & 9 & $5.96 \mathrm{E}-05$ \\
GO:0035914 & Skeletal muscle celldifferentiation & 5 & $1.08 \mathrm{E}-04$ \\
GO:0006935 & Chemotaxis & 6 & $1.82 \mathrm{E}-04$ \\
GO:0032496 & Response to lipopolysaccharide & 6 & $3.58 \mathrm{E}-04$ \\
GO:0045944 & Positive regulation oftranscription from RNApolymerase II promoter & 14 & $4.11 \mathrm{E}-04$ \\
GO:0043065 & Positive regulation of apoptoticprocess & 8 & $4.96 \mathrm{E}-04$ \\
GO:0006366 & Transcription from RNApolymerase II promoter & 7 & $8.04 \mathrm{E}-04$ \\
GO:0070098 & Chemokine-mediatedsignaling pathway & 4 & 0.001213338
\end{tabular}

Count, the number of DEGs involved in GO terms. DEGs, differentially expressed genes; GO, Gene Ontology

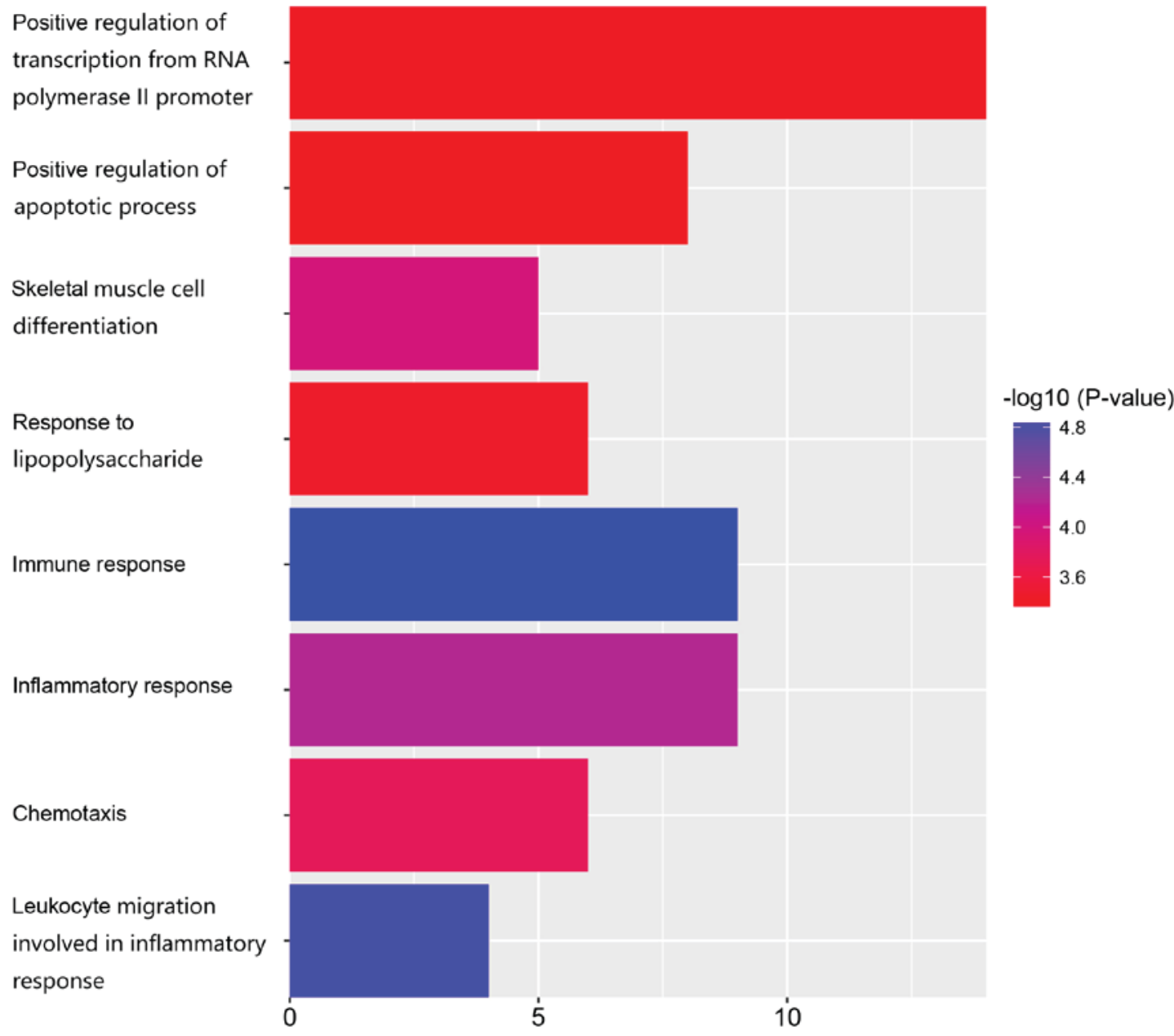

Figure 2. GO biological process for DEGs. P-value are shown in different colors, from red to blue, meaning decreasing P-value. The number of DEGs involved in GO terms are shown in $X$-axle. DEGs, differentially expressed genes; GO, Gene Ontology.

\section{Discussion}

In the current study, 114 DEGs were recognized in the liver tissue from two groups of 1-year-old mice. The expression was significantly different between $90 \mathrm{~min}$ of ischemia and
$90 \mathrm{~min}$ of ischemia followed by $1 \mathrm{~h}$ of reperfusion. Based on the pathway enrichment analysis, most DEGs enriched in immune response, leukocyte migration involved in inflammatory response, and inflammatory response, including genes like CXCL1, PLSCR1, IL6, CCL2, PROCR, PPBP, VPREB2, 
Table III. KEGG pathway analysis for DEGs (top 10).

\begin{tabular}{llll}
\hline KEGG ID & \multicolumn{1}{c}{ KEGG Term } & Count & P-value \\
\hline mmu04668 & TNF signaling pathway & 8 & $1.57 \mathrm{E}-06$ \\
mmu05144 & Malaria & 6 & $5.41 \mathrm{E}-06$ \\
mmu05164 & Influenza A & 8 & $3.28 \mathrm{E}-05$ \\
mmu04010 & MAPK signaling pathway & 8 & $3.72 \mathrm{E}-04$ \\
mmu05166 & HTLV-I infection & 8 & $6.71 \mathrm{E}-04$ \\
mmu05143 & African trypanosomiasis & 4 & $8.72 \mathrm{E}-04$ \\
mmu05323 & Rheumatoid arthritis & 5 & $8.93 \mathrm{E}-04$ \\
mmu04915 & Estrogen signaling pathway & 5 & 0.001899238 \\
mmu05134 & Legionellosis & 4 & 0.003588248 \\
mmu05169 & Epstein-Barr virus infection & 6 & 0.005803772
\end{tabular}

Count, the number of DEGs involved in KEGG terms. KEGG, Kyoto Encyclopedia of Genes and Genomes; DEGs, differentially expressed genes.

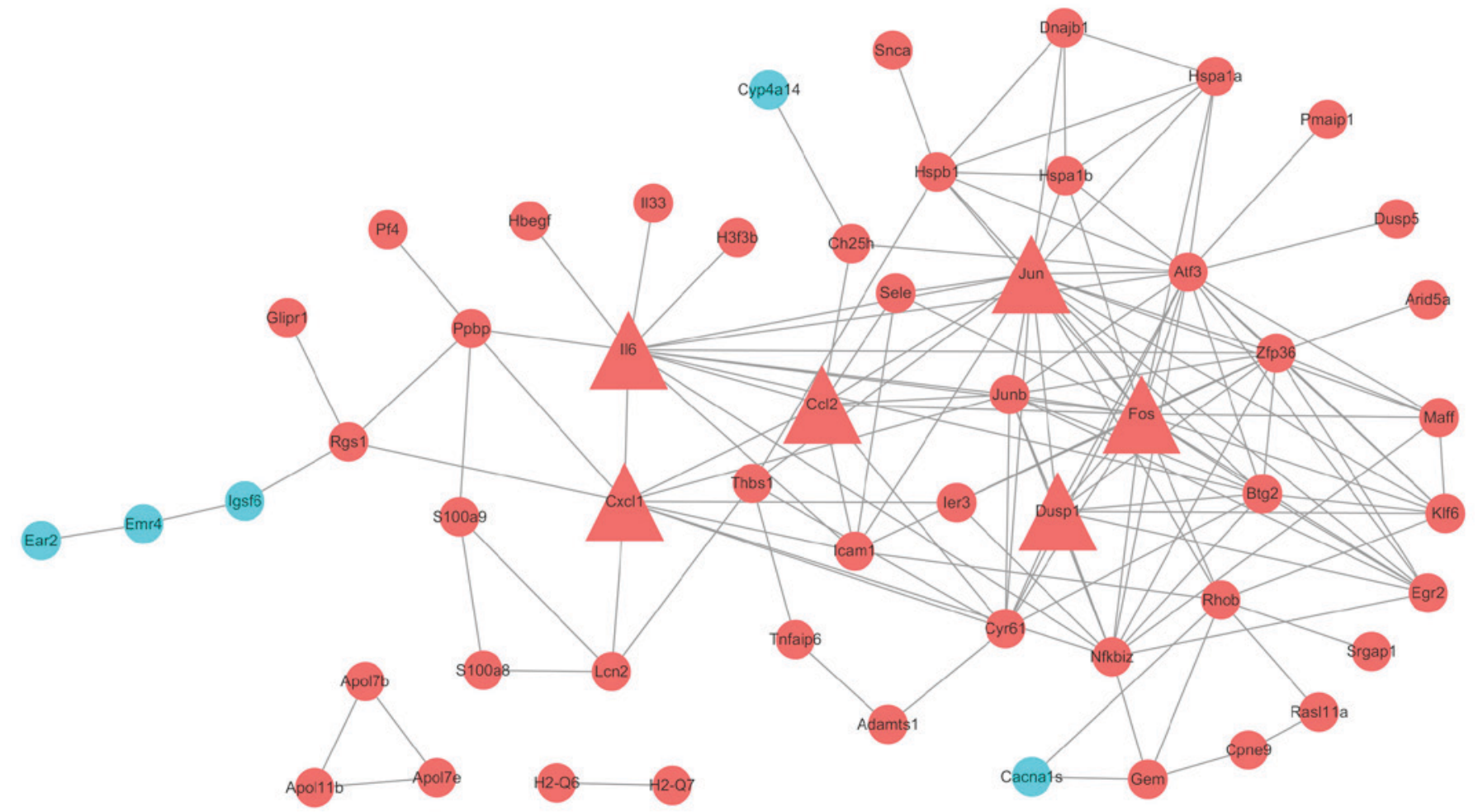

Figure 3. Target genes interaction network in liver ischemia and reperfusion. Hub genes are labeled by triangles. Upregulated and downregulated expression are shown in red and blue severally.

VPREB1, PF4, S100A8, S100A9, NFKBIZ, THBS1, and SELE. TNF signaling pathway and MAPK signaling pathway were recognized with highest count and low P-value. In PPI network, CXCL1, CCL2, IL6, JUN, FOS and DUSP1 were hub proteins.

In our results, the expression of CXCL1 and IL6 increased rapidly in $90 \mathrm{~min}$ of ischemia followed by $1 \mathrm{~h}$ of reperfusion, suggesting that reperfusion could induce severer damage or more organs dysfunction. CXCL1, also known as GRO- $\alpha$, could be a therapeutic target with further research. For instance, depletion of CXCL1 can lessen angiogenesis activity and reduce tumor growth. AS a member of the CXC chemokine family, it involved in recruitment of leukocytes and their migration, and many other inflammatory conditions (18). Gomez-Rodriguez et al (19) discovered that the expression of CXCL1 can be regulated by MMP-10. The latter was necessary for tissue repair by inhibiting CXCL1. In vivo, pre-emptive hypoxia-regulated Haem oxygenase-1 (pHRE-HO-1) could reduce the level of IL6 and CXCL. It was helpful for tissue regeneration and thus alleviating critical limb ischemia injury (20). Ahuja et al (21) first proved that serum IL6 had an essential role in AKI-mediated lung neutrophil accumulation 


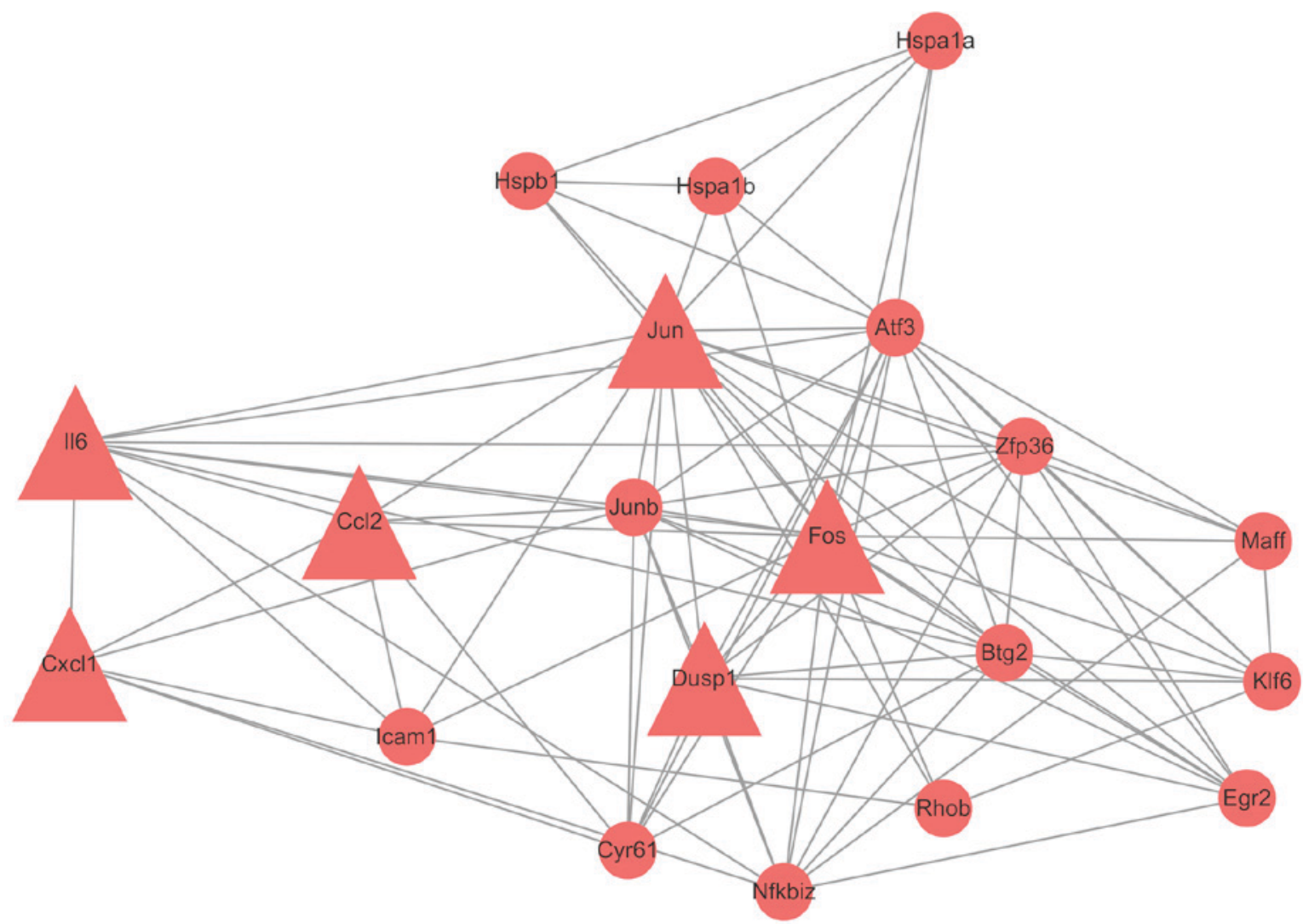

Figure 4. Network of target genes with node degree $\geq 6$.

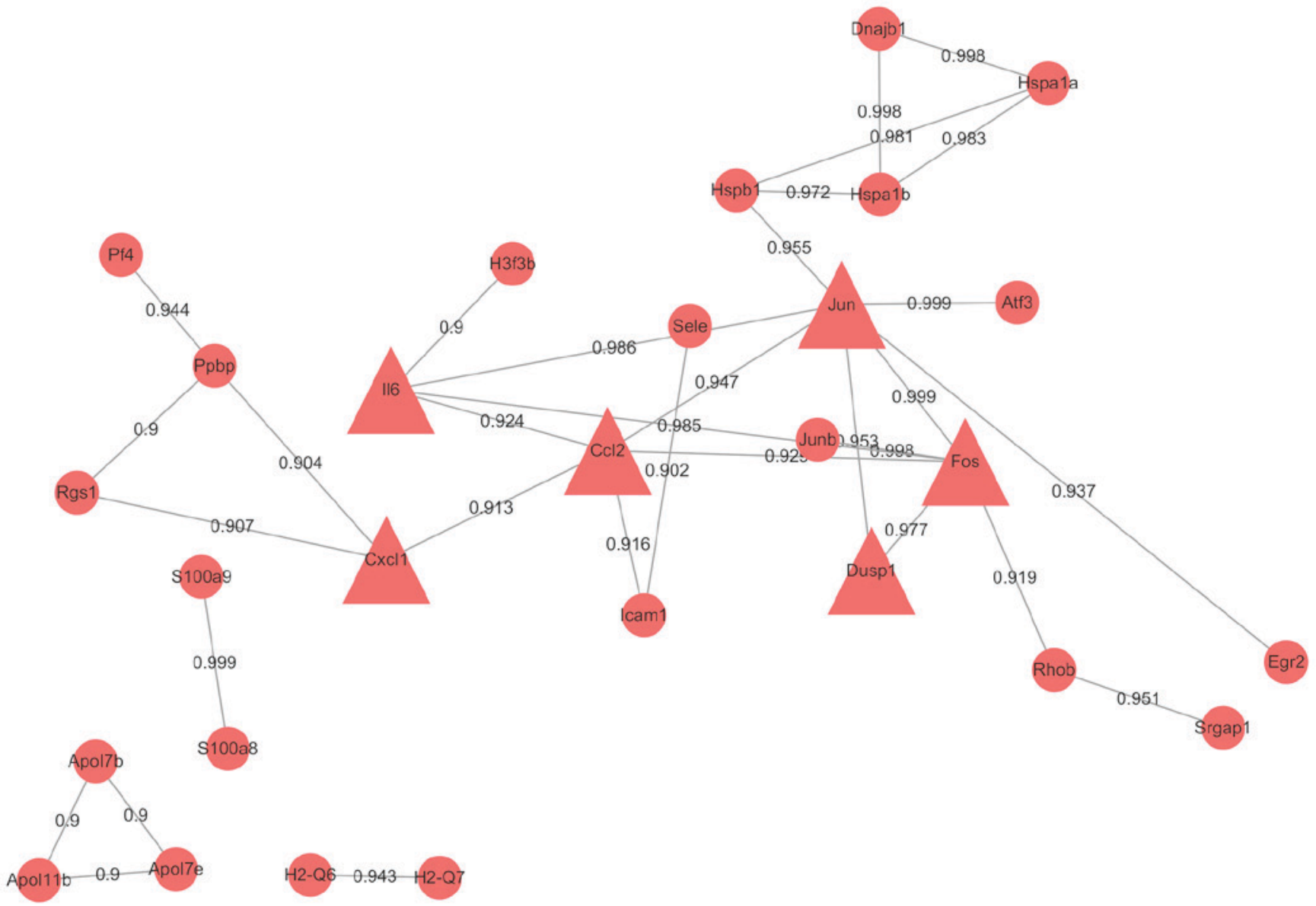

Figure 5. Network of target genes with edge combined score $\geq 0.9$. 
and lung injury by stimulating CXCL1 production in lung, which indicated that inhibition of CXCL1 may be a possible therapy of lung injury after AKI. Hepatic stellate cells (HSCs) had a significant effect on I/R- and endotoxin-induced acute hepatocyte injury. When suppressing the function of HSCs, the expression of TNF $\alpha$, neutrophil chemoattractant CXCL1 and endothelin-A receptor were all decreased (22).

Our study also identified that CCL2 was upregulated in $\mathrm{I} / \mathrm{R}$ group. It might indicate that reperfusion could aggravate inflammation reaction. Much research had tried to confirm the relationship between CCL2 and inflammation. For example, CCL2-CCR2 signaling could accelerate liver I/R injury, for the reason that CCL2 attracted inflammatory monocytes and CCR2-expressing neutrophil to move into liver from bone marrow (23). Heil et al (24) stated that CCL2, was related to the accumulation of macrophages in growing collateral vessels. In mouse femoral artery excision model, CCL2 and CCR2, played an important role in post-ischemic regenerative processes of skeletal muscle (25). CCL2/CCR2 dominated post-ischemic vessel growth (26). Zhang et al (27) found that in retinal vascular inflammation, the production of CCL2 required NAD (P) H oxidase activity.

The other three key genes in this study are JUN, FOS and DUSP1. Expression of FOS and DUSP1 were substantially elevated in stroke patients (28).

We analyzed the gene microarray data from a new point, the damage of reperfusion per se, while Huber et al (8) studied liver I/R injury emphasizing on the impact of age. There were some limitations of our study. Firstly, for the lack of preconditioning data, we can't continue to mine biological function under the circumstance of precondition or other more relations. Kapoor et al (29) proposed that liver ischemic preconditioning activated MAPK signaling pathway, permitting hepatocytes to sustain secondary damage. Oyaizu et al (30) suggested that in rat pulmonary ischemia-reperfusion models, Src PTK activation was the major reason for reperfusion-induced lung injury but not gene expression alteration. Secondly, GSE10657 only consisted of reperfusion data of one time point. We couldn't compare gene expression changes between different time points of reperfusion.

In conclusion, our study provides supplementary evidence for the hypothesis that Reperfusion itself creates injury during liver I/R. We identified 114 DEGs between Reperfusion following Ischemia and Ischemia alone. CXCL1, CCL2, IL6, JUN, FOS and DUSP1 were key genes in I/R injury. These genes may be the potential therapeutic target. However, more experimental researches are needed to verify.

\section{Acknowledgements}

This study was supported by The Natural Scientific Foundation of Guangdong Province (2016A030313255) and The Foundation of Sun Yat-sen University for Young Teachers (16ykpy36).

\section{References}

1. Li Y, Yang Y, Feng Y, Yan J, Fan C, Jiang S and Qu Y: A review of melatonin in hepatic ischemia/reperfusion injury and clinical liver disease. Ann Med 46: 503-511, 2014.
2. Zhai Y, Petrowsky H, Hong JC, Busuttil RW and Kupiec-Weglinski JW: Ischaemia-reperfusion injury in liver transplantation-from bench to bedside. Nat Rev Gastroenterol Hepatol 10: 79-89, 2013.

3. Papadopoulos D, Siempis T, Theodorakou E and Tsoulfas G: Hepatic ischemia and reperfusion injury and trauma: Current concepts. Arch Trauma Res 2: 63-70, 2013.

4. Tanaka Y, Maher JM, Chen C and Klaassen CD: Hepatic ischemia-reperfusion induces renal heme oxygenase-1 via NF-E2-related factor 2 in rats and mice. Mol Pharmacol 71: 817-825, 2007.

5. Lee SM, Park MJ, Cho TS and Clemens MG: Hepatic injury and lipid peroxidation during ischemia and reperfusion. Shock 13: 279-284, 2000

6. Calkins CM, Bensard DD, Moore EE, McIntyre RC, Silliman CC Biffl W, Harken AH, Partrick DA and Offner PJ: The injured child is resistant to multiple organ failure: A different inflammatory response? J Trauma 53: 1058-1063, 2002.

7. Okaya T, Blanchard J, Schuster R, Kuboki S, Husted T, Caldwell CC,Zingarelli B, Wong H, Solomkin JS and Lentsch AB: Age-dependent responses to hepatic ischemia/reperfusion injury. Shock 24: 421-427, 2005.

8. Huber N, Sakai N, Eismann T, Shin T, Kuboki S, Blanchard J, Schuster R, Edwards MJ, Wong HR and Lentsch AB: Age-related decrease in proteasome expression contributes to defective nuclear factor-kappaB activation during hepatic ischemia/reperfusion. Hepatology 49: 1718-1728, 2009.

9. Jaeschke H and Woolbright BL: Current strategies to minimize hepatic ischemia-reperfusion injury by targeting reactive oxygen species. Transplant Rev (Orlando) 26: 103-114, 2012.

10. Abu-Amara M, Yang SY, Seifalian A, Davidson B and Fuller B: The nitric oxide pathway-evidence and mechanisms for protection against liver ischaemia reperfusion injury. Liver Int 32: 531-543, 2012.

11. Zaouali MA, Boncompagni E, Reiter RJ, Bejaoui M, Freitas I, Pantazi E, Folch-Puy E, Abdennebi HB, Garcia-Gil FA and Roselló-Catafau J: AMPK involvement in endoplasmic reticulum stress and autophagy modulation after fatty liver graft preservation: A role for melatonin and trimetazidine cocktail. J Pineal Res 55: 65-78, 2013.

12. Eltzschig HK and Collard CD: Vascular ischaemia and reperfusion injury. Br Med Bull 70: 71-86, 2004.

13. Cai J, Perkumas KM, Qin X, Hauser MA, Stamer WD and Liu Y: Expression profiling of human schlemm's canal endothelial cells from eyes with and without glaucoma. Invest Ophthalmol Vis Sci 56: 6747-6753, 2015.

14. Ritchie ME, Phipson B, Wu D, Hu Y, Law CW, Shi W and Smyth GK: limma powers differential expression analyses for RNA-sequencing and microarray studies. Nucleic acids Res 43: e47, 2015 .

15. Ashburner M, Ball CA, Blake JA, Botstein D, Butler $\mathrm{H}$, Cherry JM, Davis AP, Dolinski K, Dwight SS, Eppig JT, et al: Gene ontology: Tool for the unification of biology. The gene ontology consortium. Nat Genet 25: 25-29, 2000.

16. Kanehisa M, Goto S, Sato Y, Furumichi M and Tanabe M: KEGG for integration and interpretation of large-scale molecular data sets. Nucleic Acids Res 40 (Database issue): D109-D114, 2012.

17. Szklarczyk D, Franceschini A, Wyder S, Forslund K, Heller D, Huerta-Cepas J, Simonovic M, Roth A, Santos A, Tsafou KP, et al: STRING v10: Protein-protein interaction networks, integrated over the tree of life. Nucleic Acids Res 43 (Database issue): D447-D452, 2015.

18. Bechara C, Chai H, Lin PH, Yao Q and Chen C: Growth related oncogene-alpha (GRO-alpha): Roles in atherosclerosis, angiogenesis and other inflammatory conditions. Med Sci Monit 13: RA87-RA90, 2007.

19. Gomez-Rodriguez V, Orbe J, Martinez-Aguilar E, Rodriguez JA, Fernandez-Alonso L, Serneels J, Bobadilla M, Perez-Ruiz A, Collantes M, Mazzone M, et al: Functional MMP-10 is required for efficient tissue repair after experimental hind limb ischemia. FASEB J 29: 960-972, 2015.

20. Jazwa A, Stepniewski J, Zamykal M, Jagodzinska J, Meloni M, Emanueli C, Jozkowicz A and Dulak J: Pre-emptive hypoxia-regulated HO-1 gene therapy improves post-ischaemic limb perfusion and tissue regeneration in mice. Cardiovasc Res 97: 115-124, 2013.

21. Ahuja N, Andres-Hernando A, Altmann C, Bhargava R, Bacalja J, Webb RG, He Z, Edelstein CL and Faubel S: Circulating IL-6 mediates lung injury via CXCL1 production after acute kidney injury in mice. Am J Physiol Renal Physiol 303: F864-F872, 2012. 
22. Stewart RK, Dangi A, Huang C, Murase N, Kimura S, Stolz DB Wilson GC, Lentsch AB and Gandhi CR: A novel mouse model of depletion of stellate cells clarifies their role in ischemia/reperfusion- and endotoxin-induced acute liver injury. J Hepatol 60 298-305, 2014.

23. Zhang J, Xu P, Song P, Wang H, Zhang Y, Hu Q, Wang G, Zhang S, Yu Q, Billiar TR, et al: CCL2-CCR2 signaling promotes hepatic ischemia/reperfusion injury. J Surg Res 202: 352-362, 2016.

24. Heil M, Ziegelhoeffer T, Wagner S, Fernández B, Helisch A Martin S, Tribulova S, Kuziel WA, Bachmann G and Schaper W: Collateral artery growth (arteriogenesis) after experimental arterial occlusion is impaired in mice lacking CC-chemokine receptor-2. Circ Res 94: 671-677, 2004

25. Contreras-Shannon V, Ochoa O, Reyes-Reyna SM, Sun D, Michalek JE, Kuziel WA, McManus LM and Shireman PK: Fat accumulation with altered inflammation and regeneration in skeletal muscle of CCR2-/-mice following ischemic injury. Am J Physiol Cell Physiol 292: C953-C967, 2007.

26. Cochain C, Rodero MP, Vilar J, Récalde A, Richart AL, Loinard C,Zouggari Y, Guérin C, Duriez M, Combadière B, et al: Regulation of monocyte subset systemic levels by distinct chemokine receptors controls post-ischaemic neovascularization. Cardiovasc Res 88: 186-195, 2010.
27. Zhang W, Rojas M, Lilly B, Tsai NT, Lemtalsi T, Liou GI, Caldwell RW and Caldwell RB: NAD(P)H oxidase-dependent regulation of CCL2 production during retinal inflammation. Invest Ophthalmol Vis Sci 50: 3033-3040, 2009.

28. Adamski MG, Li Y, Wagner E, Yu H, Seales-Bailey C, Soper SA, Murphy M and Baird AE: Expression profile based gene clusters for ischemic stroke detection. Genomics 104: 163-169, 2014.

29. Kapoor S, Berishvili E, Bandi S and Gupta S: Ischemic preconditioning affects long-term cell fate through DNA damage-related molecular signaling and altered proliferation. Am J Pathol 184: 2779-2790, 2014

30. Oyaizu T, Fung SY, Shiozaki A, Guan Z, Zhang Q, dos Santos CC, Han B, Mura M, Keshavjee S and Liu M: Src tyrosine kinase inhibition prevents pulmonary ischemia-reperfusion-induced acute lung injury. Intensive Care Med 38: 894-905, 2012. 